\title{
The Clinical Utility of Patient-Measured Blood Pressure at Home in the Management of Hypertension
}

Richard A. Dart, MD

Keywords:

Blood pressure;

Ambulatory blood pressure monitoring; Hypertension;

Self care
Reprint Requests:

Richard A. Dart, MD

Department of Nephrology

Marshfield Clinic

1000 North Oak Avenue

Marshfield, WI 54449

Tel: 7I5-387-5345

Fax: 7|5-389-3808

Email: dart.richard@marshfieldclinic.org
I

n a recent issue of Clinical Medicine \& Research, Celis et al. ${ }^{1}$ presented information about the growing importance of the role of self-measurement of blood pressure at home (home self-BP) in the overall management of a patient's blood pressure (BP) and, in particular, as a possible predictor of cardiovascular risk. The Seventh Report of the Joint National Committee on Prevention, Detection, Evaluation, and Treatment of High Blood Pressure ${ }^{2}$ (JNC 7) guideline gives a relatively brief commentary on the role for home self-BP measurement, but one which is generally supportive of its use. The main points from this guideline relate to the unique potential of home self-BP measurement to assist in deciding 1) whether to use ambulatory monitoring, 2) whether anti-hypertensive medication might be withheld if blood pressures are less than 130/80 $\mathrm{mm} \mathrm{Hg}$ and no target organ damage is noted and 3) whether it has usefulness as an assessment of blood pressure in smokers. ${ }^{2}$ However, nothing in JNC 7 specifically relates home self-BP measurement with the prediction of future cardiovascular risk. Alternately, the Guidelines for the Management of Hypertension: Report of the Fourth Working Party of the British Hypertension Society

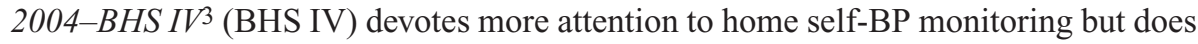
so with a cautionary note. The BHS IV report specifically states that while the number of readings which might be useful are recommended, no recommendations are given as to the exact role of long-term home self-BP monitoring and how to best use those readings in direct clinical application of blood pressure management.

Both Celis et al. ${ }^{1}$ and BHS IV 3 discuss at some length the lack of evidence that home self-BP measurements will add more to the prediction of cardiovascular disease risk than that which is possible with office readings alone. However, Celis et al. ${ }^{1}$ provide some very important data and discussion from the Treatment of Hypertension Based on Home or Office Blood Pressure (THOP) study ${ }^{4}$ which may contribute to clarifying how home self-BP measurement might lead to better control of blood pressure and cardiovascular outcomes. 
Some important cautions are given in both JNC 7 and BHS $\mathrm{IV}$ and relate to the various devices available for home self-BP measurement, the need for careful monitoring of the type of device used and whether patients correctly take their BP. ${ }^{2,3}$ To the practicing clinician all these issues are very important, yet despite the lack of more specific guidelines as to frequency of obtaining readings, or the best time of day to do so, the use of home self-BP monitoring is commonly employed. In reviewing Marshfield Clinic's experience over the last few years, it appears home self-BP monitoring had been mostly for the purposes of comparing office BP to home readings. It has also been used to help in making decisions regarding antihypertensive therapy and in considering using ambulatory BP monitoring (B. Weister, personal communication).

In clinical practice, concerns about making patients overly anxious about their BP, without adding real benefit in their management, can arise. Further, although some suggestions have been presented in BHS IV, 3 the number of readings that should be made has not been firmly established. Chatellier and colleagues ${ }^{5}$ found that the reproducibility of home self-BP is dependent upon the number of readings made with best results obtained when at least 30 measurements are made over a 5-day period (3 per day). However, other studies have shown only 2 days $^{6}$ or 3 days 7,8 of monitoring are necessary to provide reliable and reproducible values. There is additional disagreement over whether the first-day measurements should be excluded to help improve the reproducibility of home self-BP measurements. $6,9-11$ Other studies of the accuracy of home self-BP measurements, as determined by agreement with average ambulatory BP values, demonstrated clinically useful results could be achieved with as few as two home self-BP measurements in 1 day. ${ }^{12} \mathrm{~A}$ recent Japanese study ${ }^{13}$ that tried to identify the most useful frequency of home self-BP measurements as a predictor of cardiovascular risk, specifically stroke, found that the risk value increased as the number of readings rose from 1 to 14 . However, Celis et al. ${ }^{1}$ noted that this study employed unusual home measurement schedules, namely, a single morning measurement.

Thus, the clinical usefulness of home self-BP monitoring is not completely clear. In our Marshfield Clinic patient population, we did not specifically capture the reasons for patient referral to the Patient Education Department for training in taking home self-BP measurements nor did we record how those measurements were specifically used in the management of the patient's blood pressure. Thus, at present, we do not know what the exact impact of home self-BP measurement has had on intervention inclusive of changes in therapy, further evaluation for secondary causes or referral for a 24-hour ambulatory BP monitoring. Further, in-depth analysis of these pooled home self-BP measurements has not yet been attempted in our patient data to determine similarities with other studies. ${ }^{12}$ From the raw data collected at Marshfield Clinic, it is interesting to note that the home self-BP measurement counselings have declined through the last
Table 1. Home self-BP utilization at Marshfield Clinic.

\begin{tabular}{llllll}
\hline & \multicolumn{5}{c}{ Year } \\
\cline { 2 - 6 } & $\mathbf{2 0 0 0}$ & $\mathbf{2 0 0 1}$ & $\mathbf{2 0 0 2}$ & $\mathbf{2 0 0 3}$ & $\mathbf{2 0 0 4}$ \\
\hline Counseling & 394 & 349 & 209 & 137 & 129 \\
Screening & 336 & 273 & 143 & 113 & 151 \\
\hline BP: Blood pressure; Home self-BP: Patient monitoring of BP at home.
\end{tabular}

4 years (table 1), but the reason for this decline is not known. It would also be interesting to compile data on age, sex, and co-morbidities of patients utilizing home self-BP monitoring.

The common reasons for obtaining home self-BP measurements often relate to office versus home reading disparities, initiation of changes in BP medication, concerns over reported adverse BP at home (i.e. orthostatic symptoms) and disparities between morning and later day BP readings (personal observation). Thus, home self-BP measurement training and use as a tool in clinical practice are done fairly frequently at Marshfield Clinic, although the reasons for ordering home measurements and how the data gathered is utilized in the care of the patient needs to be studied.

In practice, patients are asked to record BP measurements at least once a day with mornings being the most common time of measurement. If this reading is elevated, the patient is asked to repeat the reading after 10 to 15 minutes and is also warned to check for proper technique. Patients are also asked to keep a diary of readings and events that might have affected their BP (e.g., whether BP medications have been taken or pre-instructed dose adjustments have occurred). Readings at different times of the day may also be required to provide a broader representation of a given day's BP, in essence, a randomly-obtained form of ambulatory BP monitoring.

Beyond these more basic reasons to have patients record home blood pressure readings, Celis et al. ${ }^{1}$ noted that home self-BP measurement may have a possible impact in predicting cardiovascular outcomes and that the THOP findings may lead to more specific guidelines and recommendations for the use of home self-BP monitoring allowing it to serve more directly in the management of BP therapy. However, additional studies are required to clarify such statements and before changes can be implemented. Several studies are currently underway that may provide additional useful information on the role of home self-BP measurements in the management of the patient with high BP and the prediction of cardiovascular risk. ${ }^{4,14-16}$

As BP monitors for patient use become more available, and as the ease of taking home self-BP readings increases, and as patient interest in self-BP monitoring increases, it is anticipated that home self-BP monitoring and its direct use in clinical practice will increase. Further, as patients are now 
encouraged to take a more active and direct role in their own medical care, the impetus to utilize home self-BP monitoring takes on greater importance and calls for evaluating the definition of its role in patient care and refining its value and validity in BP management.

\section{References}

1. Celis H, Den Hond E, Staessen JA. Self-measurement of blood pressure at home in the management of hypertension. Clin Med Res 2005;3:19-26.

2. Chobanian AV, Bakris GL, Black HR, Cushman WC, Green LA, Izzo JL Jr, Jones DW, Materson BJ, Oparil S, Wright JT Jr, Roccella EJ; Joint National Committee on Prevention, Detection, Evaluation, and Treatment of High Blood Pressure. National Heart, Lung, and Blood Institute; National High Blood Pressure Education Program Coordinating Committee. Seventh report of the Joint National Committee on Prevention, Detection, Evaluation, and Treatment of High Blood Pressure. Hypertension 2003;42:1206-1252.

3. Williams B, Poulter NR, Brown MJ, Davis M, McInnes GT, Potter JF, Sever PS, McG Thom S; British Hypertension Society. Guidelines for management of hypertension: report of the fourth working party of the British Hypertension Society, 2004-BHS IV. J Hum Hypertens 2004;18:139-185.

4. Staessen JA, Den Hond E, Celis H, Fagard R, Keary L, Vandenhoven G, O'Brien ET; Treatment of Hypertension Based on Home or Office Blood Pressure (THOP) Trial Investigators. Antihypertensive treatment based on blood pressure measurement at home or in the physician's office: a randomized controlled trial. JAMA 2004;291:955-964.

5. Chatellier G, Day M, Bobrie G, Menard J. Feasibility study of N-of1 trials with blood pressure self-monitoring in hypertension. Hypertension 1995;25:294-301.

6. Stergiou GS, Skeva II, Zourbaki AS, Mountokalakis TD. Self-monitoring of blood pressure at home: how many measurements are needed? J Hypertens 1998;16:725-731.

7. Celis H, De Cort P, Fagard R, Thijs L, Staessen JA. For how many days should blood pressure be measured at home in older patients before steady levels are obtained? J Hum Hypertens 1997;11:673-677.

8. Hond ED, Celis H, Fagard R, Keary L, Leeman M, O’Brien E, Vandenhoven G, Staessen JA; THOP investigators. Selfmeasured versus ambulatory blood pressure in the diagnosis of hypertension. J Hypertens 2003;21:717-722.

9. Imai Y, Ohkubo T, Hozawa A, Tsuji I, Matsubara M, Araki T, Chonan K, Kikuya M, Satoh H, Hisamichi S, Nagai K. Usefulness of home blood pressure measurements in assessing the effect of treatment in a single-blind placebo-controlled open trial. J Hypertens 2001;19:179-185.

10. Chatellier G, Dutrey-Dupagne C, Vaur L, Zannad F, Genes N, Elkik F, Menard J. Home self blood pressure measurement in general practice. The SMART study. Self-measurement for the Assessment of the Response to Trandolapril. Am J Hypertens 1996;9:644-652.

11. Stergiou GS, Baibas NM, Gantzarou AP, Skeva II, Kalkana CB, Roussias LG, Mountokalakis TD. Reproducibility of home, ambulatory, and clinic blood pressure: implications for the design of trials for the assessment of antihypertensive drug efficacy. Am J Hypertens 2002;15:101-104.

12. Brook RD. Home blood pressure: accuracy is independent of monitoring schedules. Am J Hypertens 2000;13:625-631.

13. Ohkubo T, Asayama K, Kikuya M, Metoki H, Hoshi H, Hashimoto J, Totsune K, Satoh H, Imai Y; Ohasama Study. How many times should blood pressure be measured at home for better prediction of stroke risk? Ten-year follow-up results from the Ohasama study. J Hypertens 2004;22:1099-1104.
14. Fujiwara T, Matsubara M, Ohkubo T, Imai Y. Study design of HOMED-BP: hypertension objective treatment based on measurement by electrical devices of blood pressure. Clin Exp Hypertens 2003;25:143-144.

15. Aoki Y, Asayama K, Ohkubo T, Nishimura T, Kikuya M, Metoki H, Hozawa A, Hashimoto J, Michimata M, Matsubara M, Araki T, Imai Y; HOMED-BP Study Group. Progress report on the HOMED-BP Study: hypertension objective treatment based on measurement by electrical devices of blood pressure study. Clin Exp Hypertens 2004;26:119-127.

16. Celis H, Staessen JA, Thijs L, Buntinx F, De Buyzere M, Den Hond E, Fagard RH, O'Brien ET; Ambulatory Blood Pressure and Treatment of Hypertension Trial Investigators. Ambulatory Blood Pressure and Treatment of Hypertension Trial Investigators. Cardiovascular risk in white-coat and sustained hypertensive patients. Blood Press 2002;11:352-356.

\section{Author Affiliation}

Richard A. Dart, MD, Department of Nephrology, Marshfield Clinic, Marshfield, Wisconsin 